COSTA CFA; MELO PCT; RAGASSI CF; LAZZARINI PRC; FERRONATO EM; MARTINS EAS; ARAÚJO TH. 2015. Crescimento da batateira em sistema de preparo profundo de solo e sucessão de poáceas. Horticultura Brasileira 33: 051-058. DOI - http://dx.doi.org/10.1590/S0102-053620150000100009

\title{
Crescimento da batateira em sistema de preparo profundo de solo e sucessão de poáceas
}

\author{
Cristiano FA Costa ${ }^{1}$; Paulo CT Melo ${ }^{1}$; Carlos F Ragassi ${ }^{2}$; Paulo RC Lazzarini ${ }^{1}$; Evandro M Ferronato ${ }^{1}$; \\ Elton AS Martins ${ }^{1}$; Thaís H Araújo ${ }^{1}$ \\ 'ESALQ, Depto. Produção Vegetal, C. Postal 9, 13418-900 Piracicaba-SP; cristianofacosta@hotmail.com; paulomelo@usp.br; paulo. \\ lazzarini@usp.br; evandro.ferronato@hotmail.com; easmartins@gmail.com; nena.pa@hotmail.com; ${ }^{2}$ Embrapa Hortaliças, C. Postal 218, \\ 70351-970 Brasília-DF; carlos.ragassi@embrapa.br
}

\section{RESUMO}

No Brasil, a batata é usualmente cultivada após a cultura do milho utilizando-se preparo de solo capaz de atingir por volta de $20 \mathrm{~cm}$ de profundidade, em que os impedimentos físicos existentes abaixo da camada preparada não são removidos. Desse modo, postula-se que a realização de preparo profundo de solo associado à sucessão com outras poáceas, tais como as forrageiras, seja uma alternativa para proporcionar maior desenvolvimento da batateira. O presente estudo, realizado com a cultivar Atlantic, teve como objetivo comparar o sistema de preparo convencional (PC) de solo adotado para a cultura da batata, em sucessão à cultura do milho, a um sistema de preparo profundo (PP), em sucessão a três diferentes poáceas (milho, capim Marandu capim Tanzânia) quanto à dinâmica do crescimento da batateira. A produção em matéria seca $(\mathrm{MS}, \mathrm{t} / \mathrm{ha})$ da parte aérea das poáceas variou conforme: Tanzânia PP $(26,56)>$ Marandu PP $(19,94)$ $>$ Milho PP $(5,57)=$ Milho PC $(5,720)$. Com relação ao desenvolvimento da cultura da batata, para produção respectivamente de raízes e de folhas (g/planta de MS), o tratamento Milho PP $(5,56$ e 85,51) foi superior ao Milho PC (4,34 e 64,83), não se verificando diferença estatística entre os demais tratamentos. Para a produção de hastes, o tratamento Milho PC (5,53 g/planta MS) foi inferior a todos os tratamentos e para a produção de tubérculos, Marandu PP e Milho PP (152,16 e 149,01 g/planta MS) foram superiores ao tratamento milho PC (115,73 g/planta MS). Verificou-se assim, que o preparo profundo de solo, de forma geral, proporcionou maior desenvolvimento da batateira e que os seus efeitos em alguns parâmetros de crescimento variaram conforme a espécie de poácea utilizada em sucessão.

Palavras-chave: Solanum tuberosum, batata, curva de crescimento, preparo de solo, sucessão de culturas, produtividade.

\begin{abstract}
Growth of potato under deep tillage and succession with grass types

Potato in Brazil is often cultivated after corn (Zea mays) using the conventional tillage system, which achieve about $20 \mathrm{~cm}$ depth, not deep enough to remove physical impairments below the prepared layer. Thus, a deep tillage system associated to succession with grass types is postulated as an alternative to promote the adequate development of the potato crop. This study, with the cultivar Atlantic, aimed to compare the conventional tillage (PC) used in potato, in succession to corn, to a deep tillage system (PP), in succession with three different grass types (corn, Brachiaria brizantha cv. Marandu and Panicum maximum cv. Tanzânia) on the growth dynamics of potato. The dry matter production (MS, t/ha) of the aboveground part of the grasses was different in descending order: Tanzânia PP (26.56) > Marandu PP (19.94) > Corn PP (5.57) = Corn PC (5.72). With respect to potato development, Corn PP (5.56 and 85.51) was higher than Corn PC (4.34 and $64.83 \mathrm{~g} /$ plant MS) for the production of roots and leaves respectively, no statistical difference being found among the other treatments. For the production of stalks, Corn PC $(5.53 \mathrm{~g} /$ plant MS) was the lowest and for the production of tubers, Marandu PP and Corn PP (152.16 and $149.01 \mathrm{~g} / \mathrm{plant}$ MS) were higher than Corn PC (115.73 g/plant MS). In summary, the deep tillage system provided better development of potato and the effects varied depending on the grass type used for succession.
\end{abstract}

Keywords: Solanum tuberosum, growth curve, tillage, succession, productivity.

(Recebido para publicação em 10 de dezembro de 2013; aceito em 10 de outubro de 2014) (Received on December 10, 2013; accepted on October 10, 2014)

\begin{abstract}
To panorama olerícola nacional, 1 a cultura da batata (Solanum tuberosum) se destaca por sua importância socioeconômica, sendo praticada por um expressivo contingente de pequenos produtores. No quinquênio 2007-2011, enquanto a produção e a produtividade de batata aumentaram 11 e $12 \%$, respectivamente, a área teve
\end{abstract}

acréscimo de apenas 1\%. Na safra 2012, a produção brasileira alcançou 3,50 milhões de $\mathrm{t}$, a área colhida foi de 130,4 mil ha e a produtividade $26,81 \mathrm{t} / \mathrm{ha}$. Em relação à safra anterior, houve um decréscimo de produção de $11 \%$. Também em 2012, a região Sudeste participou com 56,94\% da produção nacional, a Sul com $35,1 \%$, a
Centro-Oeste com 3,44\% e a Nordeste com 4,6\%. Os estados de Minas Gerais, São Paulo e Paraná detiveram respectivamente $33,8 \%, 22,8 \%$ e $21,4 \%$ da produção total (IBGE, 2013).

O sistema de produção da batata em geral utiliza sucessão de culturas com o milho e preparo de solo realizado com implementos de ação pouco 
profunda (em torno de $20 \mathrm{~cm}$ ), tais como a grade aradora, que podem gerar impedimentos físicos em subsuperfície (Ragassi et al., 2009) e que, em tese, são prejudiciais ao desenvolvimento da batateira. Considerando-se que as raízes da batateira podem alcançar 60 a $80 \mathrm{~cm}$ de profundidade (Stalham et al., 2007), um sistema de preparo de solo profundo, com alcance de até $70 \mathrm{~cm}$, associado ao cultivo de diferentes poáceas, tem sido avaliado em um experimento de longo prazo na ESALQ em Piracicaba-SP, que pretende verificar a evolução da produtividade e da ocorrência de doenças de solo na cultura da batata nos sistemas de preparo (profundo, em associação a diferentes gramíneas, e convencional, associado à sucessão com milho).

Aumento de até $16 \%$ na produtividade da cultura da batata em decorrência da utilização do preparo profundo foi obtido no segundo ano de avaliação, não tendo sido verificada, até então, influência na ocorrência de doenças de solo (Ragassi et al., 2009). Um estudo específico do efeito desse sistema sobre o desenvolvimento da batateira, no entanto, ainda não foi realizado.

A produção de matéria seca (MS) é priorizada nas diferentes partes das plantas de acordo com os quatro estádios fenológicos. O estádio I ou período vegetativo tem início após a quebra de dormência das gemas, quando ocorre a produção de brotos. A MS é acumulada rapidamente através do desenvolvimento intenso das raízes e da parte aérea, partindo da emergência e indo até o início da formação dos tubérculos. O estádio II, ou período de tuberização, tem início com a formação dos tubérculos nas pontas dos estolões e vai até o início do enchimento dos primeiros tubérculos. Embora a formação de tubérculos continue durante o próximo estádio de desenvolvimento, aqueles que definirão a produção formam-se no estádio II. O estádio III, ou período de enchimento dos tubérculos, é caracterizado por uma taxa de aumento constante de massa e tamanho. A parte aérea continua a crescer, porém os aumentos na massa de material seco total são, na maior parte, devidos aos tubérculos. Este é o estádio mais longo e vai até a maturação. O estádio IV, ou período de maturação, é marcado pelo início do amarelecimento dos caules e a senescência das folhas, indo até o final do ciclo (Biemond \& Vos, 1992).

A análise de crescimento de plantas baseia-se no fato de que cerca de $90 \%$ da MS acumulada ao longo do seu desenvolvimento resulta da atividade fotossintética e o restante da absorção de nutrientes minerais. Dessa forma, é possível avaliar o crescimento final da planta como um todo e a contribuição dos diferentes órgãos no crescimento total (Barcelos et al., 2007). O entendimento do padrão de partição de MS entre as partes da planta, a variação desse padrão e os efeitos das condições ambientais sobre o processo podem ajudar na escolha da melhor cultivar para cada propósito e maximizar a produtividade de tubérculos com características desejáveis (Tekalign \& Hammes, 2005). Portanto, a análise de crescimento e o estudo da partição da MS entre os órgãos da planta geram conhecimentos que podem facilitar a tomada de decisões relativas ao manejo da cultura (Pohl et al., 2009). Sabe-se também, que na ausência de uma curva de absorção de nutrientes, a produção de matéria seca (MS) fornece uma boa aproximação do acúmulo de nutrientes (Sousa \& Coelho, 2001). Os fatores associados à produção de MS na cultura da batata são qualidade do tubérculo semente, práticas culturais, maturidade dos tubérculos, disponibilidade hídrica, eficiência fotossintética e adubação (Fageria et al., 1997).

A presente pesquisa foi realizada com objetivo de comparar o efeito de dois sistemas de preparo de solo para a cultura da batata: 1) preparo convencional ou raso e 2) preparo profundo ou proposto associado ao cultivo em sucessão de poáceas (Panicum maximum cv. Tanzânia, Brachiaria brizantha cv. Marandu e Zea mays híbrido 'AG 6080') quanto ao desenvolvimento da batateira cultivar Atlantic.

\section{MATERIAL E MÉTODOS}

O estudo é de longo prazo e foi instalado em outubro de 2006 (Ragassi, 2009) em um Nitossolo Eutrófico típico textura argilosa, no município de Piracicaba-SP ( $22^{\circ} 42^{\prime} \mathrm{S}, 47^{\circ} 38^{\prime} \mathrm{O}$, altitude $\left.569 \mathrm{~m}\right)$. O presente experimento corresponde ao sexto ciclo de sucessão poáceas - batata (2011-2012) e, para sua instalação, os atributos químicos do solo foram verificados por meio de análise química (Embrapa, 1997), que demonstraram, para a camada de $0-20 \mathrm{~cm}$, valores de $\mathrm{pH}=5,5$, matéria orgânica $=19 \mathrm{~g} / \mathrm{dm}^{3}, \mathrm{P}$, $\mathrm{S}-\mathrm{SO}_{4}, \mathrm{Cu}, \mathrm{Fe}, \mathrm{Zn}, \mathrm{Mn}$ e B= 52; 11; 6,6; $30 ; 8,3 ; 27,6$ e $0,4 \mathrm{mg} / \mathrm{dm}^{3}$ e $\mathrm{K}, \mathrm{Ca}, \mathrm{Mg}$, $\mathrm{Al}$ e $\mathrm{CTC}=4,5 ; 53 ; 16 ; 0$ e $108 \mathrm{mmol}_{\mathrm{c}} /$ $\mathrm{dm}^{3}$. Para a camada de $20-40 \mathrm{~cm}, \mathrm{pH}=$ 5,8 , matéria orgânica $=14 \mathrm{~g} / \mathrm{dm}^{3}, \mathrm{P}$, $\mathrm{S}_{-} \mathrm{SO}_{4}, \mathrm{Cu}, \mathrm{Fe}, \mathrm{Zn}, \mathrm{Mn}$ e B=20,0; 33,0; 4,$9 ; 29,0 ; 2,0 ; 24,4$ e $0,39 \mathrm{mg} / \mathrm{dm}^{3}$ e K, $\mathrm{Ca}, \mathrm{Mg}, \mathrm{Al}$ e $\mathrm{CTC}=3,5 ; 51,0 ; 18,5 ; 0,0$ e $107,0 \mathrm{mmol} / \mathrm{dm}^{3} \mathrm{e}$, finalmente, para a camada de $40-80 \mathrm{~cm}, \mathrm{pH}=5,8$, matéria orgânica $=8,5 \mathrm{~g} / \mathrm{dm}^{3}, \mathrm{P}, \mathrm{S}_{-} \mathrm{SO}_{4}, \mathrm{Cu}, \mathrm{Fe}$, $\mathrm{Zn}, \mathrm{Mn}$ e $\mathrm{B}=9,5 ; 67,0 ; 2,4 ; 11,0 ; 0,9 ; 8,0$ e $0,39 \mathrm{mg} / \mathrm{dm}^{3}$ e K, Ca, $\mathrm{Mg}$, Al e CTC= 2,$0 ; 47,0 ; 17,0 ; 0$ e $91,0 \mathrm{mmol}_{\mathrm{c}} / \mathrm{dm}^{3}$.

Foram estudados quatro tratamentos, de forma fixa na área experimental. Três tratamentos foram realizados em preparo profundo de solo e um em preparo convencional (controle), as operações de preparo tendo sido realizadas em todos os anos no início de cada cultivo (poácea e batata).

Cada um dos tratamentos em preparo profundo correspondeu a uma espécie de poácea utilizada anteriormente à cultura da batata: $\mathrm{T} 1=$ sucessão $P$. maximum $\mathrm{cv}$. Tanzânia - batata, sob preparo profundo (Tanzânia PP), T2= sucessão $B$. brizantha cv. Marandu - batata, sob preparo profundo (Marandu PP) e T3= sucessão milho (Zea mays 'AG 6080') - batata, sob preparo profundo (Milho PP). O preparo convencional foi realizado em apenas um tratamento, utilizando-se a cultura do milho como antecessora à da batata, T4= sucessão milho (Zea mays 'AG 6080') - batata, em preparo convencional (Milho PC), de forma a representar o manejo convencionalmente adotado para a batata. Cada ciclo de sucessão equivaleu a um ano e englobou um ciclo da poácea (outubro a maio) e um ciclo de batata (maio a agosto).

A cultivar de batata adotada foi Atlantic, escolhida por ser a mais plantada no Brasil visando o segmento de batata industrializada na forma de chips (ABBA, 2013).

As unidades experimentais foram 
constituídas por três canteiros, com duas linhas cada um, de 10,0 m de comprimento, sendo o espaçamento entre os canteiros equivalente a $1,0 \mathrm{~m} \mathrm{e}$, entre as duas linhas dentro do canteiro, de $80 \mathrm{~cm}$. Um esquema detalhado das medidas utilizadas no preparo profundo e convencional pode ser visualizado em Ragassi et al. (2009).

O canteiro central da unidade experimental foi preservado para possibilitar a avaliação da produtividade por área, que não foi escopo do presente artigo. Para o presente estudo, que avaliou a dinâmica de crescimento da batata realizando-se amostras destrutivas das plantas, a linha de plantio mais próxima ao canteiro central foi utilizada como parcela, preservando-se, ainda, as linhas mais externas da unidade experimental como bordadura.

O preparo de solo e a semeadura das poáceas ( $1^{\mathrm{a}}$ etapa) para sucessão com a batata foram realizados em outubro de 2011. A dessecação mecânica (corte) das poáceas foi feita no mês de abril de 2012 e o preparo de solo e plantio da batata $\left(2^{\mathrm{a}}\right.$ etapa), no mês de maio de 2012.

Para o preparo do solo destinado à semeadura das poáceas, em todos os tratamentos foi empregada a enxada rotativa Rotin (Mafes Agromecânica), que gira no sentido anti-horário (inverso às tradicionais disponíveis no mercado) e trabalha sob alta rotação.

No preparo convencional, após a operação com a enxada rotativa, o terreno foi gradeado a $20 \mathrm{~cm}$ de profundidade. Nos tratamentos com o preparo profundo, após a operação com a enxada rotativa, o solo foi subsolado no centro do canteiro (1,80 $\mathrm{m}$ de bitola do trator), a $70 \mathrm{~cm}$ de profundidade com a haste subsoladora modelo Dreno (Mafes Agromecânica). Em seguida, o solo foi preparado com uma enxada rotativa encanteiradora de baixa rotação modelo Turbo (Mafes Agromecânica) a $40 \mathrm{~cm}$ de profundidade, incorporando os restos de cultura e fertilizantes.

Em sequência, procedeu-se a semeadura a lanço das forrageiras utilizando-se $5 \mathrm{~kg} /$ ha de sementes puras e viáveis para os capins Tanzânia e Marandu. Para o milho, foi estabelecido o estande de 65.000 plantas/hectare com espaçamento de $60 \mathrm{~cm}$ entre linhas e 25 $\mathrm{cm}$ entre plantas na linha.

O preparo para o plantio da cultura da batata ( $2^{\text {a }}$ etapa) começou após o corte das poáceas. Inicialmente, as espigas de milho foram colhidas quando os grãos atingiram sua maturidade fisiológica. Em abril de 2012, a massa das forrageiras e as plantas de milho sem espiga foram roçadas e picadas com uso de um implemento de trincha com facas modelo Triton e permaneceram na superfície do solo até que apresentassem aspecto seco. Posteriormente, a massa seca e algumas brotações foram trituradas novamente com o emprego do implemento de trincha com martelos Tribar (Mafes Agromecânica). Logo após essa operação, foi empregada novamente a enxada rotativa Rotin, superficialmente, para promover a "capina" das poáceas.

Após essa etapa, começaram as operações de preparo de solo para o plantio da cultura de batata. No preparo de solo profundo, foi utilizada a haste subsoladora Dreno seguida pela enxada rotativa encanteiradora de baixa rotação modelo Turbo. Para o preparo convencional, foi utilizada apenas grade aradora a $20 \mathrm{~cm}$.

No final do mês de maio, foi feito o plantio mecanizado da batata utilizando-se a plantadora Ecoplan (Mafes Agromecânica). Quando ocorreu a emergência dos brotos, 15 dias após o plantio, foi realizada a amontoa por meio do implemento Gaia (Mafes Agromecânica).

De acordo com o histórico de produtividade de milho na área, foi feita adubação nos tratamentos com essa cultura considerando-se exportação (colheita) de 6,0 t de grãos. Nos capins Marandu e Tanzânia, como não há exportação de nutrientes da área, foi feita a semeadura sem adubação, aproveitando-se os resíduos de fertilizantes do ciclo anterior da batata. As doses dos fertilizantes para batateira foram definidas conforme as necessidades nutricionais da planta, baseando-se nos teores observados na análise química do solo, teores foliares de nutrientes e sintomas visuais de deficiência. Os fertilizantes utilizados na adubação de base foram uréia; superfosfato simples; Kmag; produbor e zincodur; com o objetivo de fornecer $45 \mathrm{~kg} / \mathrm{ha}$ de $\mathrm{N}, 200 \mathrm{~kg} / \mathrm{ha}$ de $\mathrm{P}_{2} \mathrm{O}_{5}, 100$ $\mathrm{kg} / \mathrm{ha}$ de $\mathrm{K}_{2} \mathrm{O}, 5 \mathrm{~kg} / \mathrm{ha}$ de $\mathrm{B}$ e $10 \mathrm{~kg} / \mathrm{ha}$ de $\mathrm{Zn}$. O corretivo utilizado foi gesso agrícola na quantidade de 1,0 t/ha.

Foram utilizados tubérculos inteiros de 4-6 cm de diâmetro, provenientes de $3^{\mathrm{a}}$ geração clonal, plantados mecanicamente no dia 23 de maio de 2012 . O espaçamento entre plantas foi de 28,5 $\mathrm{cm}$ na linha de plantio, $80 \mathrm{~cm}$ entre linhas no canteiro e 1,0 m entre linhas no rodado (entre canteiros), resultando em uma população de 38.986 plantas/ha.

Para o manejo fitossanitário, foram realizadas pulverizações de acordo com o Sistema de Alerta Fitossanitário de Wallin (1962). Para irrigação, foi utilizado o critério de Marouelli et al. (1996).

As coletas de plantas utilizadas para estabelecer as curvas de crescimento, bem como determinação de área foliar, foram realizadas a cada 14 dias. Foram coletadas duas plantas por parcela seguindo-se dois critérios: seleção de plantas que sempre estivessem rodeadas por outras plantas de porte e estande adequados, evitando-se assim a coleta de plantas que superestimariam ou subestimariam os resultados devido ao efeito de bordadura; e seleção visual das plantas, coletando-se apenas aquelas que melhor representassem a média da população de plantas presentes na parcela. As plantas foram transportadas em bandejas diretamente ao laboratório, onde foram cuidadosamente separadas do solo com uso de água. Para que as plantas não murchassem e comprometessem a análise de área foliar, a atividade foi realizada sempre no período da manhã. Após lavagem das amostras, as plantas tiveram seus órgãos separados em raízes, hastes, folhas e tubérculos.

As medições de área foliar $\left(\mathrm{cm}^{2} /\right.$ planta) foram realizadas no momento da chegada das plantas no laboratório, com a utilização de integrador de área foliar modelo LI 300 (LI-COR). A biomassa das raízes, dos tubérculos, das hastes e folhas foi seca em estufa até se obter massa constante, medida em balança analítica. Para construção da curva de crescimento, foram feitas seis coletas de plantas. A primeira foi realizada aos 35 dias após o plantio (DAP) e as subsequentes a cada 14 dias, somando-se seis coletas $(35,49,63,77,91$ e 105 DAP); exceto para massa seca de tubérculos, inexistentes na coleta aos 35 DAP. Foi, 
então, adicionada uma coleta aos 119 DAP para determinação da massa de tubérculos.

Coletou-se a parte aérea das plantas em 1,0 $\mathrm{m}^{2}$ de cada parcela. A fitomassa coletada foi submetida à pesagem e dela retirou-se uma amostra de aproximadamente $100 \mathrm{~g}$, que foi seca em estufa a $65^{\circ} \mathrm{C}$ por 24 horas para obtenção do teor de água. $\mathrm{O}$ resultado foi convertido em produção de matéria seca por unidade de área ( $\mathrm{t} / \mathrm{ha})$.

Utilizou-se o delineamento em blocos casualizados, com quatro tratamentos (Milho PC, Tanzânia PP, Marandu PP, Milho PP) e seis repetições. Os dados obtidos foram submetidos à análise de variância (ANOVA, $\mathrm{p} \leq 0,05$ ). Para atender as pressuposições para a realização da ANOVA, algumas variáveis foram transformadas: i) produção de matéria seca da parte aérea das poáceas, matéria seca de raízes e hastes para $\log _{10}(\mathrm{x})$ e ii) área foliar e matéria seca de folhas e tubérculos para $\sqrt{x}$. Posteriormente, as médias foram comparadas pelo teste de Tukey ao nível de $5 \%$ de significância.

Para construção da curva de crescimento e distribuição de fotoassimilados, as variáveis foram analisadas em esquema fatorial (tratamentos x épocas de coleta). Foi utilizada a análise de regressão para avaliar o comportamento de cada tratamento ao longo do período experimental e adotado o teste de Tukey a $5 \%$ de probabilidade para comparar as médias dos tratamentos dentro de cada época de coleta.

\section{RESULTADOS E DISCUSSÃO}

Houve diferença entre a produção de matéria seca da parte aérea das poáceas utilizadas, na seguinte ordem decrescente: Tanzânia PP > Marandu PP > Milho $\mathrm{PP}=$ Milho PC. A massa seca produzida pela parte aérea do capim Tanzânia em preparo profundo (PP) foi de 26,56 t/ha em 150 dias de acúmulo. A alta produtividade do capim Tanzânia é característica intrínseca quando cultivado em solos muito férteis (Embrapa, 2013). Quanto ao capim Marandu em PP, o acúmulo de MS foi de 17,94 t/ha em 150 dias. Tal valor é baixo se comparado aos de Fer-

Tabela 1. Médias de matéria seca (MS) acumulada em raízes, hastes, folhas e tubérculos de batata, em relação ao tipo de preparo de solo e da espécie de poácea utilizada em sucessão \{means of dry matter (MS) accumulated in roots, stalks, leaves and tubers of potato depending on tillage and the grass type used for succession\}. Piracicaba, ESALQ, 2012.

\begin{tabular}{lllll}
\hline \multirow{2}{*}{ Tratamento } & Raízes & Hastes & \multicolumn{1}{c}{ Folhas } & Tubérculos \\
\cline { 2 - 5 } & \multicolumn{5}{c}{ (g/planta) } \\
\hline Milho PC & $4,34 \mathrm{~b}$ & $5,53 \mathrm{~b}$ & $64,83 \mathrm{~b}$ & $115,73 \mathrm{~b}$ \\
Tanzânia PP & $5,51 \mathrm{ab}$ & $8,39 \mathrm{a}$ & $72,27 \mathrm{ab}$ & $140,17 \mathrm{ab}$ \\
Marandu PP & $5,16 \mathrm{ab}$ & $9,69 \mathrm{a}$ & $73,71 \mathrm{ab}$ & $152,16 \mathrm{a}$ \\
Milho PP & $5,56 \mathrm{a}$ & $8,43 \mathrm{a}$ & $85,51 \mathrm{a}$ & $149,02 \mathrm{a}$ \\
\hline CV (\%) & $20,97 *$ & $13,81^{* *}$ & $11,84^{*}$ & $11,54 *$ \\
\hline
\end{tabular}

Os tratamentos correspondem a dois tipos de preparo de solo, preparo convencional (PC) e preparo profundo (PP), associados à sucessão de batata com diferentes espécies de poáceas [milho (Zea mays), capim Tanzânia (Panicum maximum cv. Tanzânia) e capim Marandu (Brachiaria brizantha cv. Marandu)]. Medidas equivalem à média de seis coletas aos 35, 49, $63,77,91$ e 105 dias após o plantio (DAP), exceto para massa de tubérculos, cujos valores correspondem a uma coleta realizada aos 119 DAP. $*=$ significativo a $5 \%$ de probabilidade; $* *=$ significativo a $1 \%$ de probabilidade pelo teste de Tukey \{treatments correspond to two tillage systems [conventional (PC) and deep tillage (PP)] associated with different grass types used in succession to potato [milho = corn (Zea mays), Tanzânia (Panicum maximum cv. Tanzânia) and Marandu (Brachiaria brizantha cv. Marandu)]. Values are the mean of six samples at 35, 49, 63, 77, 91 and 105 days after planting (DAP), except for the mass of tubers, which corresponds to a sample collected at 119 DAP. $*=$ significant at 5\%; **= significant at $1 \%$ by Tukey test $\}$.

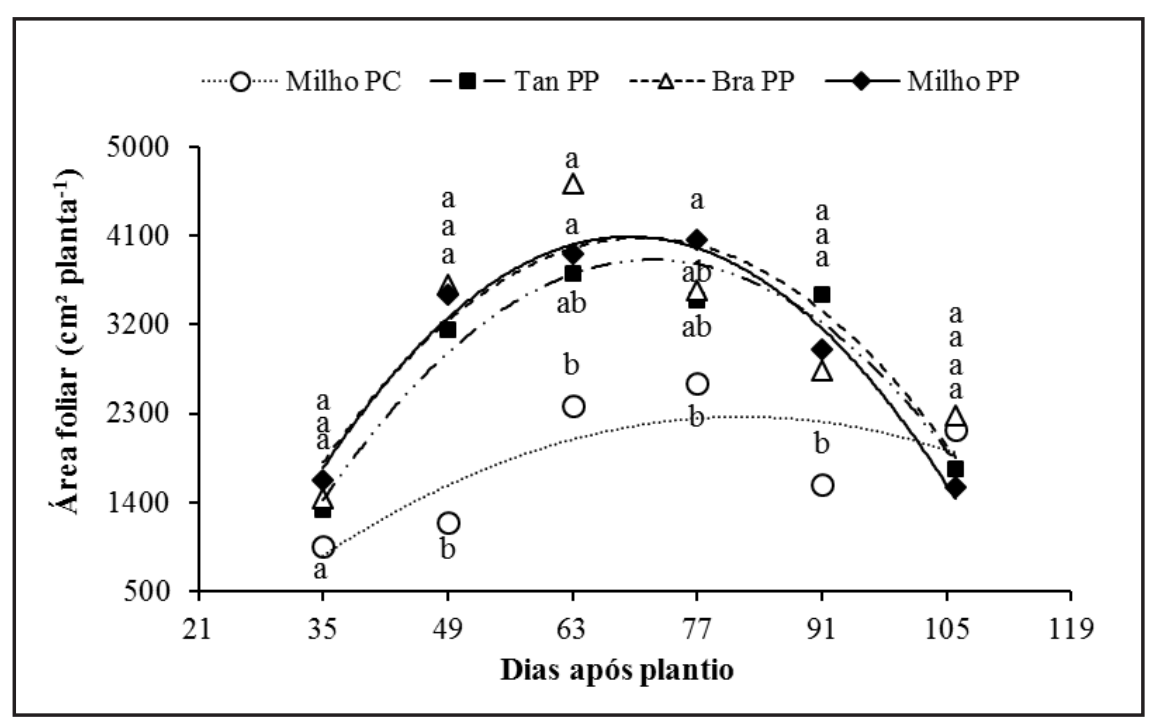

Figura 1. Evolução da área foliar da batateira cultivada em sucessão a três poáceas [milho (Milho), Panicum maximum cv. Tanzânia (Tan) e Brachiaria brizantha cv. Marandu (Bra)] em preparo profundo (PP) e a milho em preparo convencional (Milho PC) de solo \{leaf area development of potato cultivated in succession with three grass types [corn (Milho), Panicum maximum cv. Tanzânia (Tan) and Brachiaria brizantha cv. Marandu (Bra)] under deep tillage (PP) or in succession with corn under conventional tillage (Milho PC) $\}$. Milho $\mathrm{PC}, \mathrm{y}=-0,6348 \mathrm{x}^{2}+104,1 \mathrm{x}-2000,6\left(\mathrm{R}^{2}=0,6162\right)$ Pto. máximo (highest value) $=82$ dias (days); Tan PP, $y=-1,7698 x^{2}+254,93 x-5324,5\left(R^{2}=0,9449\right)$ Pto. máximo (highest value) $=72$ dias (days); Bra PP, $y=-1,7819 x^{2}+251,87 x-4822,7\left(R^{2}=0,7684\right)$ Pto. máximo (highest value $)=71$ dias (days); Milho PP, $y=-1,9777 x 2+274,38 x-5427,1\left(R^{2}=0,9757\right)$ Pto. máximo (highest value) $=69$ dias (days). Piracicaba, ESALQ, 2012.

reira (2001), que reportou um acúmulo de $23 \mathrm{t} /$ ha de MS em período similar. Especula-se que a baixa produção esteja relacionada à ocorrência de competição, no início do desenvolvimento do capim Marandu, com o capim marmelada (Brachiaria plantaginea), abundante na área e de difícil controle seletivo em 


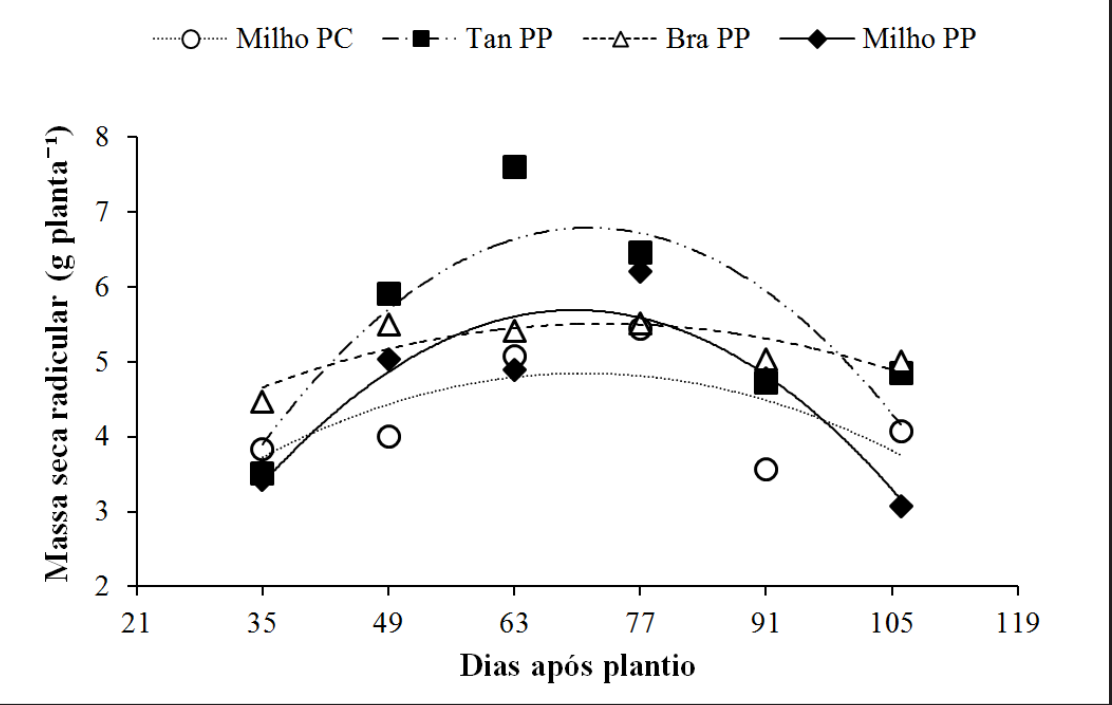

Figura 2. Evolução do acúmulo de massa seca das raízes da batateira cultivada em sucessão a três poáceas [milho (Milho), Panicum maximum cv. Tanzânia (Tan) e Brachiaria brizantha cv. Marandu (Bra)] em preparo profundo (PP) e a milho em preparo convencional (Milho PC) de solo \{root development of potato cultivated in succession with three grass types [corn (Milho), Panicum maximum cv. Tanzânia (Tan) and Brachiaria brizantha cv. Marandu (Bra)] under deep tillage and in sucession with corn under conventional tillage (Milho PC) $\}$. Milho $P C, y=-0,000027 x^{2}+0,01017 x-0,2975\left(R^{2}=0,3105^{\text {ns }}\right)$ Pto. máximo (highest value) $=76$ dias (days); Tan PP, $y=-0,00019 x^{2}+0,0272 x-0,1643\left(R^{2}=0,7290^{* *}\right)$ Pto. máximo (highest value $)=72$ dias (days); Bra PP, $y=-0,000063 \mathrm{x}^{2}+0,0097 \mathrm{x}+0,3565\left(\mathrm{R}^{2}=0,7222^{\text {ns }}\right)$ Pto. máximo (highest value) $=75$ dias (days); Milho $P P, y=-0,000198 \mathrm{x}^{2}+0,0272 \mathrm{x}-0,927\left(\mathrm{R}^{2}=\right.$ $0,9056^{* *}$ ) Pto. máximo (highest value) $=74$ dias (days). ns: não significativo (not significant); ** significativo a 1\% de probabilidade (significant at 1\%). Piracicaba, ESALQ, 2012.

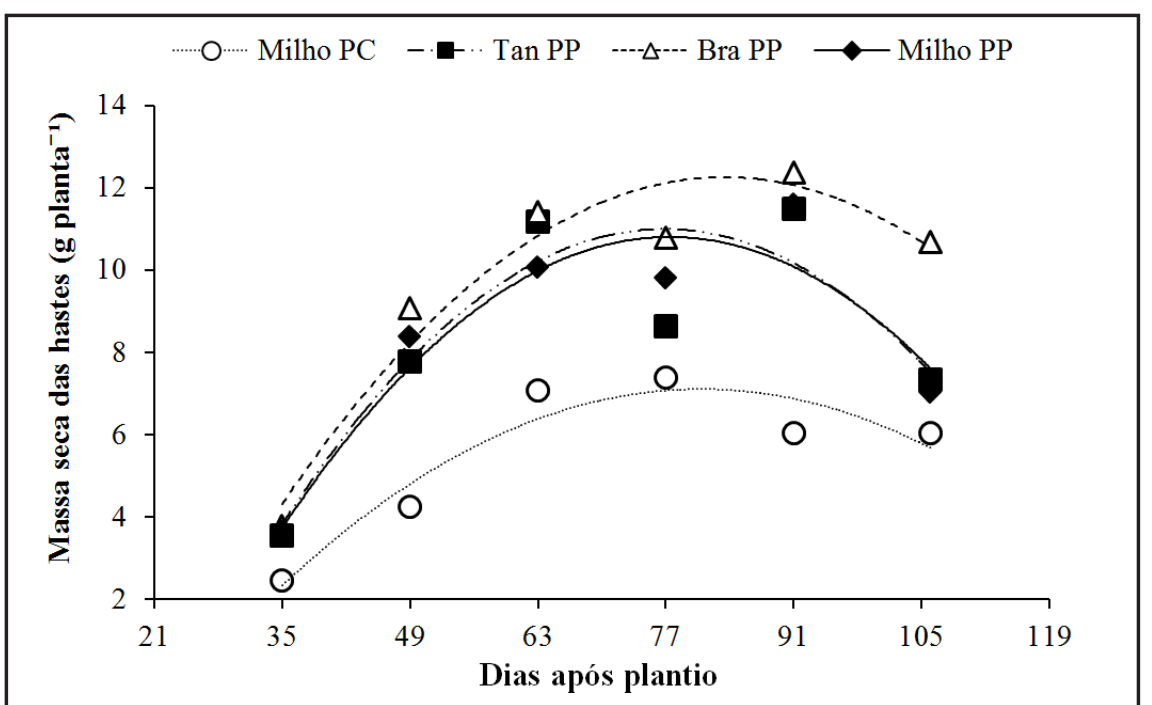

Figura 3. Evolução do acúmulo de massa seca de hastes da batateira cultivada em sucessão a três poáceas [milho (Milho), Panicum maximum cv. Tanzânia (Tan) e Brachiaria brizantha cv. Marandu (Bra)] em preparo profundo (PP) e a milho em preparo convencional (Milho PC) de solo sstalk development of potato cultivated in succession with three grass types [corn (Milho), Panicum maximum cv. Tanzânia (Tan) and Brachiaria brizantha cv. Marandu (Bra) ] under deep tillage and in succession with corn under conventional tillage (Milho PC) . Milho PC, $\mathrm{y}=-0,00022 \mathrm{x}^{2}+0,035758 \mathrm{x}-0,595336\left(\mathrm{R}^{2}=0,9485^{* *}\right)$ Pto. máximo (highest value $)=80$ dias (days); Tan PP, $y=-0,000234 x^{2}+0,037242 x-0,442546\left(R^{2}=0,8847^{* *}\right)$ Pto. máximo $=79$ dias (days); Bra PP, $\mathrm{y}=-0,00022 \mathrm{x}^{2}+0,036271 \mathrm{x}-0,392016\left(\mathrm{R}^{2}=0,8952^{* *}\right)$ Pto. máximo $=83$ dias (days); Milho PP, $y=-0,000255 x^{2}+0,03949 x-0,480293\left(R^{2}=\right.$ $0,9239^{* *}$ ) Pto. máximo $=76$ dias (days). $* *$ significativo a $1 \%$ de probabilidade (significant at 1\%). Piracicaba, ESALQ, 2012. culturas de folha estreita. A produção de palhada nos tratamentos Milho PC $(5,72$ t/ha) e Milho PP (5,56 t/ha) não diferiu estatisticamente entre si. Tal equidade deve-se, ao que tudo indica, à ausência de déficit hídrico acentuado, bem como à alta fertilidade do solo, que atendeu às exigências da cultura mesmo nas condições de preparo convencional.

Verificou-se nítida diferença na evolução da área foliar por planta entre o tratamento cultivado em preparo raso e os demais, cultivados em preparo profundo (Figura 1), o que está provavelmente relacionado às melhores condições de desenvolvimento da batateira proporcionadas por esse sistema. A batata sob o tratamento Milho PP exibiu um crescimento da área foliar $80 \%$ maior e $18 \%$ mais rápido, atingindo em seu ponto máximo $4089,29 \mathrm{~cm}^{2} /$ planta aos 69 DAP, em comparação ao Milho PC, que atingiu em seu ponto máximo 2267,20 $\mathrm{cm}^{2} /$ planta aos 82 DAP, ou seja, 13 dias depois. A área foliar nos tratamentos em preparo profundo não demonstrou diferença entre si. Tal comportamento demonstrou que o preparo profundo proporcionou desenvolvimento maior e mais rápido do aparato fotossintético, fator que pode contribuir com a produção, diretamente ligada à fotossíntese. A área foliar, considerada como parte funcional produtiva da planta, afeta diretamente seu índice de eficiência (Hunt, 1982). O preparo profundo pode ter proporcionado maior exploração do solo pelas raízes da batateira e, portanto, incrementado a disponibilidade hídrica (Ragassi et al., 2011), ocasionando o desenvolvimento superior observado na área foliar. Tal resultado é corroborado pelos dados reportados em estudos sobre disponibilidade hídrica em batata (Dar \& Rosário, 1981; Hang \& Miller, 1986).

As relações entre o estresse hídrico e o desenvolvimento das plantas são muito complexas, pelo elevado número de processos fisiológicos envolvidos, os quais são afetados de modos e intensidades diferentes. Entretanto, sabe-se que o estresse hídrico atua direta e fisicamente, causando redução no crescimento das plantas pela diminuição da turgescência celular e exercendo um efeito negativo, principalmente na fase inicial da expansão celular (Krudev, 


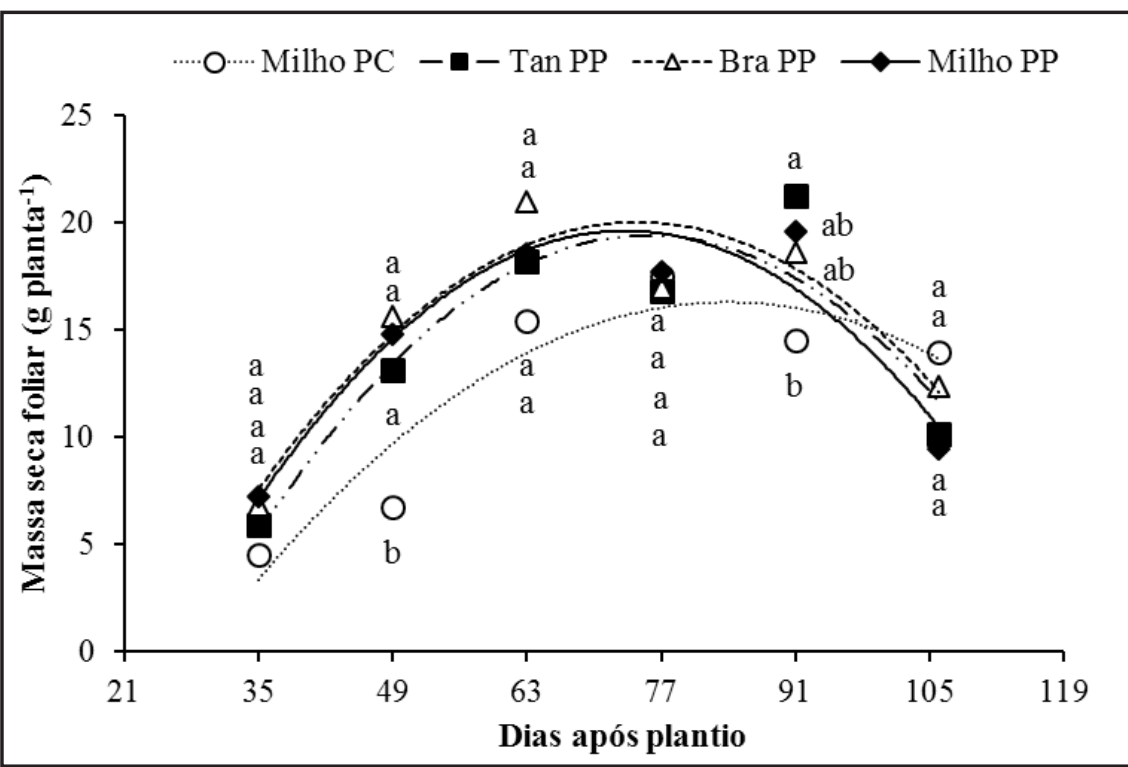

Figura 4. Evolução do acúmulo de massa seca de folhas da batateira cultivada em sucessão a três poáceas [milho (Milho), Panicum maximum cv. Tanzânia (Tan) e Brachiaria brizantha cv. Marandu (Bra)] em preparo profundo (PP) e a milho em preparo convencional (Milho PC) de solo \{leaf mass development of potato cultivated in succession with three grass types [corn (Milho), Panicum maximum cv. Tanzânia (Tan) and Brachiaria brizantha cv. Marandu (Bra)] under deep tillage and in rotation with corn under conventional tillage (Milho PC) . Milho PC: $\mathrm{y}=-0,000849 \mathrm{x}^{2}+0,14359 \mathrm{x}-2,000076\left(\mathrm{R}^{2}=0,9054^{* *}\right)$ Pto. máximo (highest value $)=77$ dias (days); Tan PP: $y=-0,001216 x^{2}+0,184307 x-2,533859\left(R^{2}=0,8914 * *\right)$ Pto. máximo (highest value) $=76$ dias (days); Bra PP: $y=-0,001099 x^{2}+0,165078 x-1,68487$ $\left(\mathrm{R}^{2}=0,8908^{* *}\right)$ Pto. máximo (highest value $)=74$ dias (days); Milho PP: $\mathrm{y}=-0,001202 \mathrm{x}^{2}$ $+0,176306 \mathrm{x}-1,99285\left(\mathrm{R}^{2}=0,9251^{* *}\right)$ Pto. máximo (highest value) $=74$ dias (days). ** significativo a 1\% de probabilidade (significant at 1\%) \}. Piracicaba, ESALQ, 2012.

1994). Com isso, há intensa redução da taxa de crescimento da área foliar, que se constitui num dos primeiros sintomas desse estresse (Begg \& Turner, 1976). A redução da taxa de crescimento da área foliar constitui-se numa estratégia de defesa dos vegetais (Mansfield \& Davies, 1985). Essa adaptação na cultura da batata acarreta decréscimos no acúmulo de MS, como também relataram Dar \& Rosário (1981).

Quanto ao crescimento das raízes da batata, houve diferença estatística para o acúmulo de MS radicular entre os tratamentos (Tabela 1 e Figura 2). Considerando-se a média de todas as coletas, o tratamento Milho PP (5,56 $\mathrm{g} /$ planta) proporcionou acúmulo de raízes $28 \%$ superior em comparação ao tratamento Milho PC (4,34 g/planta). Não se verificou, no entanto, diferença significativa entre os demais tratamentos. Na ocasião da coleta das plantas para a análise de crescimento, assim como em trincheiras que foram esporadicamente abertas na área experimental para simples observação, constatou-se que no preparo profundo de solo, as raízes da batateira cresceram até $70 \mathrm{~cm}$ de profundidade, enquanto no preparo convencional, se limitaram a $20 \mathrm{~cm}$. A massa superior de raízes produzida no preparo profundo certamente proporcionou a exploração de um maior volume de solo e, consequentemente, de água. Deve ser ressaltado que a regressão quadrática expõe somente o comportamento do acúmulo de MS das raízes em cada tratamento, pois não houve interação significativa entre os tratamentos e as avaliações realizadas no tempo. O tratamento Tanzânia PP mostrou o acúmulo máximo de MS nas raízes com 6,32 g/planta ou $246,55 \mathrm{~kg} /$ ha, aos 72 DAP. Esse valor é $29 \%$ a mais do que o acúmulo máximo do tratamento Milho PC, 4,88 g/planta ou 190,37 kg/ ha, aos 76 DAP.

Para crescimento das hastes da batata, de forma similar ao verificado para as demais variáveis relacionadas ao desenvolvimento da batata, o acúmulo de MS de hastes também foi favorecido pelo preparo profundo, ao passo que os tratamentos igualmente cultivados em preparo profundo não demonstraram diferença entre si (Tabela 1). Deve ser mencionado que não houve interação significativa de tratamento por tempo (Figura 3). A regressão quadrática da curva de acúmulo de MS das hastes mostra que o tratamento Marandu PP teve o acumulo máximo de $11,87 \mathrm{~g} /$ planta ou 463,09 kg/ha aos 83 DAP. Esse valor é $71 \%$ maior que o acúmulo máximo do tratamento Milho PC que foi de $6,93 \mathrm{~g} /$ planta ou $270,22 \mathrm{~kg} / \mathrm{ha}$ aos 80 DAP. Esses valores, no entanto, são consideravelmente inferiores aos $602,92 \mathrm{~kg} /$ ha obtidos por Yorinori (2003). Como o presente experimento recebeu, intencionalmente, menor adubação nitrogenada, visando reduzir o porte das plantas para auxiliar no controle do acamamento e do ferimento das hastes, isso possivelmente favoreceu o menor acúmulo máximo de MS nas hastes comparado aos dados reportados por Yorinori (2003).

De modo análogo às demais variáveis de desenvolvimento, as folhas também apresentaram diferença significativa quanto ao acúmulo de MS. No entanto, somente se diferenciaram os tratamentos milho PP e milho PC, sendo valores intermediários apresentados pelos demais tratamentos. O tratamento Milho PP resultou, na média de todas suas coletas, $85,51 \mathrm{~g} /$ planta, que é $31 \%$ superior à média apresentada pelo tratamento Milho PC (Tabela 1). A curva de acúmulo de MS foliar apresentou interação significativa tratamento $\mathrm{x}$ tempo (Figura 4).

A regressão quadrática da curva de acúmulo de MS foliar mostra que o tratamento Marandu PP apresentou o maior acúmulo de MS foliar. Observou-se para esse tratamento um aumento do acúmulo de MS foliar até os 74 DAP, quando ocorreu o acúmulo máximo de $19,80 \mathrm{~g} /$ planta ou $772,29 \mathrm{~kg} / \mathrm{ha}$. Para o tratamento Milho PC, o acúmulo foi de $16,18 \mathrm{~g} / \mathrm{planta}$ ou $630,91 \mathrm{~kg} / \mathrm{ha}$ aos 77 DAP. Esse valor é $22 \%$ inferior ao do tratamento Milho PP. Ambos os resultados são inferiores aos valores encontrados por Yorinori (2003) $(944,59$ $\mathrm{kg} / \mathrm{ha})$ e por Fernandes (2010) $(893,7$ $\mathrm{kg} / \mathrm{ha}$ ), possivelmente também devido 


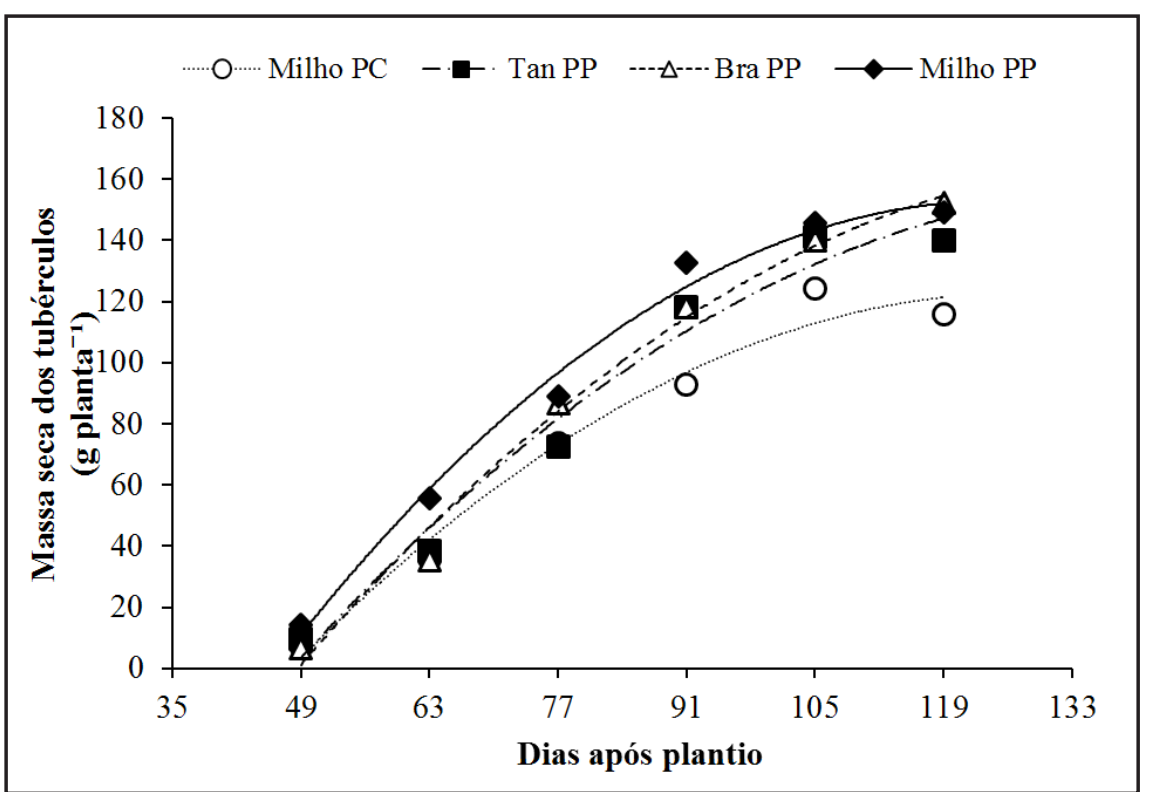

Figura 5. Acúmulo de massa seca de tubérculos de batateira cultivada em sucessão a três poáceas [milho (Milho), Panicum maximum cv. Tanzânia (Tan) e Brachiaria brizantha cv. Marandu (Bra)] em preparo profundo (PP) e a milho em preparo convencional (Milho PC) de solo \{tuber mass development of potato cultivated in succession with three grass types (corn (Milho), Panicum maximum cv. Tanzânia (Tan) and Brachiaria brizantha cv. Marandu (Bra) under deep tillage and in succession with corn under conventional tillage (Milho PC) $\}$. Milho $\mathrm{PC}, \mathrm{y}=-0,002041 \mathrm{x}^{2}+0,45921 \mathrm{x}-14,901908\left(\mathrm{R}^{2}=0,9946^{* *}\right)$ Pto. máximo (highest value) $=112$ dias (days); Tan PP, $\mathrm{y}=-0,001867 \mathrm{x}^{2}+0,442804 \mathrm{x}-14,276468\left(\mathrm{R}^{2}=0,9964^{* *}\right)$ Pto. máximo (highest value $)=119$ dias (days); Bra PP, $y=-0,002187 \mathrm{X}^{2}+0,506549 \mathrm{x}-17,120908$ $\left(\mathrm{R}^{2}=0,9971^{* *}\right)$ Pto. máximo (highest value) $=116$ dias (days); Milho PP, $\mathrm{y}=-0,002097 \mathrm{x}^{2}$ $+0,47175 \mathrm{x}-14,284583\left(\mathrm{R}^{2}=0,9975^{* *}\right)$ Pto. máximo (highest value) $=113$ dias (days). ** significativo a $1 \%$ de probabilidade (significant at 1\%). Piracicaba, ESALQ, 2012.

à menor adubação nitrogenada.

A manutenção das folhas no enchimento dos tubérculos é muito importante na obtenção de alta produtividade, pois é nessa fase que os fotossintetizados e os nutrientes minerais da parte aérea são translocados para os tubérculos (Roberts \& Dole, 1985). Além disso, no estádio de maturação dos tubérculos, o aumento da MS é resultado, principalmente, da translocação de materiais da parte aérea (Roberts \& Dole, 1985; Biemond \& Vos, 1992). Segundo Yorinori (2003), quanto mais tempo as hastes e as folhas permanecerem sadias, maior é o potencial de produtividade.

A curva de acúmulo de MS pelos tubérculos apresentou diferença entre os tratamentos, mas não houve interação significativa tratamento $\mathrm{x}$ tempo (Figura 5). Aos 119 DAP, a MS dos tubérculos acumulada pelos tratamentos Marandu PP e Milho PP foram superiores ao Milho PC, sem que houvesse diferença estatística entre os tratamentos em preparo profundo. O Milho PC apresentou o
Yorinori (2003) (25,80 t/ha) e Fernandes (2010) $(22,54 \mathrm{t} / \mathrm{ha})$.

Dessa forma, o preparo profundo proposto no presente trabalho mostrou-se eficaz para a obtenção de produtividade em níveis comparáveis aos da cultivar Atlantic em escala comercial de 25 a 30 t/ha (Galvão, 2013), independente da espécie de poácea utilizada em sucessão. Além disso, alguns aspectos do manejo devem ser considerados: (a) o espaçamento duplo adotado utiliza 1 tha (13\%) a menos de tubérculos-semente e (b) na adubação de plantio foi aplicado, aproximadamente, $50 \%$ das $2,81 \mathrm{t} / \mathrm{ha}$ de fertilizantes utilizados em média convencionalmente (ABBA, 2011). Sendo assim, mesmo se houvesse equidade nos resultados de produtividade, a menor utilização de tubérculos-semente e adubação poderia contribuir para redução de custos e, consequentemente, aumento de receitas.

Dar \& Rosário (1981), investigando respostas da cultura da batata ao estresse hídrico, observaram diminuição na taxa de crescimento da cultura sob essa condição. Por sua vez, Hang \& Miller (1986) estudaram as respostas fisiológicas da cultura da batata ao estresse hídrico e observaram redução no tamanho das plantas, no número de folhas, na taxa de crescimento da cultura e na taxa de crescimento do tubérculo. Os resultados encontrados nesses estudos corroboram os dados reportados no presente trabalho, em que se verificou maior crescimento e acúmulo de MS em todos os órgãos quando se utilizou o preparo profundo. Esse resultado provavelmente está relacionado à maior exploração do solo pela batateira com consequente incremento na absorção de água e nutrientes.

Assim, com base no que foi exposto, o preparo profundo de solo proposto no presente estudo proporcionou benefícios ao desenvolvimento da cultura da batata e os efeitos sobre alguns parâmetros de crescimento variaram em consequência da poácea utilizada em sucessão.

\section{AGRADECIMENTOS} aumento de $33 \%$ na produtividade. A produtividade do tratamento Marandu PP foi respectivamente 20 e $38 \%$ superior aos rendimentos reportados por
À Mafes Agromecânica e à Mafes Inteligência Agronômica pelo aprendi- 
zado e por proporcionar, além das máquinas para o preparo de solo e plantio da batata, todo o apoio necessário para a realização deste trabalho. Ao Grupo PACES (Projetando Agricultura Compromissada em Sustentabilidade), que vem conduzindo este experimento há sete anos. À USP-ESALQ e à CAPES pela área experimental e suporte durante a condução das atividades.

\section{REFERÊNCIAS}

ABBA. 2011, 27 de abril. Cadeia da batata. Disponível em http://www. abbabatatabrasileira.com.br/

ABBA - Associação Brasileira da Batata. 2013, 9 de setembro. Variedades de batata Atlantic. Disponível em http://www. abbabatatabrasileira.com.br/revista11_009. $\mathrm{htm} /$

BARCELOS DM; GARCIA A; MACIEL JUNIOR VA. 2007. Análise de crescimento da cultura da batata submetida ao parcelamento da adubação nitrogenada em cobertura, em um Latossolo Vermelho-Amarelo. Ciência e Agrotecnologia 31: 21-27.

BEGG JE; TURNER NC. 1976. Crop water deficits. Advances in Agronomy 28: 161-217.

BIEMOND H; VOS J. 1992. Effects of nitrogen on the development and growth of potato plant. 2. The partitioning of dry matter, nitrogen and nitrate. Annals of Botany 70: 37-45.

DAR WD; ROSÁRIO DA. 1981. Responses of white potato (Solanum tuberosum) to moisture stress. Philippine Agriculturist 64: 125-134.

EMBRAPA. 1997. Manual de métodos de análises de solo. Brasília: EMBRAPA. 212p.

EMBRAPA. 2013, 9 de setembro. Tanzânia: cultivar de Panicum maximum. Disponível em: http://www.cnpgc.embrapa.br/ produtoseservicos/pdf/tanzania.pdf/

FAGERIA NK; BALIGAR VC; JONES CA. 1997. Growth and mineral nutrition of field crops. New York: Marcel Dekker. 624p.

FERNANDES AM. 2010. Crescimento, produtividade, acúmulo e exportação de nutrientes em cultivares de batata (Solanum tuberosum). Botucatu: UNESP-FCA. 144p. (Dissertação mestrado).

FERREIRAAM. 2001. Emergência, crescimento e senescência de uma cultivar de braquiária em condições dos Cerrados. Goiânia: UFG-ICB. 46p. (Dissertação mestrado).

GALVÃO RL. 2013. Comunicação pessoal. Pepsico Elma Chips.

HANG AN; MILLER DE. 1986. Yield and physiological-responses of potato to deficit, high-frequency sprinkler irrigation. Agronomy Journal 78: 436-440.

HUNT R. 1982. Plant growth curves: the functional approach to plant growth analysis. London: E. Arnold. 248p.

IBGE. 2013, 25 de junho. Levantamento sistemático da produção agrícola. Disponível em http://www.ibge.gov.br/home/estatistica/ indicadores/agropecuaria/lspa/lspa_201304. pdf/

KRUDEV TG. 1994. Água, vida das plantas. São Paulo: Ícone, 178p.

MANSFIELD TA; DAVIES WJ. 1985. Mechanisms for leaf control of gas exchange. BioScience 35: 158-164.

MAROUELLI WA; SILVA WLC; SILVA HR. 1996. Manejo da irrigação em hortaliças. Brasília: EMBRAPA, SPI; EMBRAPA, CNPH, 72p.

POHL S; LOPES NF; BRAGA EJB; SILVA CP; SILVA FSP; PETERS JA. 2009. Características de crescimento de plantas de batata, cv. Baronesa, e seu genótipo transformado geneticamente para resistência ao PVY. Revista Ceres 56: 736-743.

RAGASSI CF. 2009. Sistema de preparo profundo de solo e sucessão de gramíneas para o plantio da batata (Solanum tuberosum). Piracicaba: USP-ESALQ. 82p. (Dissertação mestrado).

RAGASSI CF; FAVARIN JL; MELO PCT; SHIRAISHI FA; SAKO H. 2011. Qualidade do solo e sustentabilidade na cultura da batata. Scientia Agraria Paranaensis 10: 88-103.

RAGASSI CF; FAVARIN JL; SHIRAISHI FA; MOITA AW; SAKO H; MELO PCT. 2009. Efeito da descompactação profunda de solo na produção da cultura da batata. Horticultura Brasileira 27: 484-489.

ROBERTS S; DOLE RE. 1985. Potassium nutrition of potatoes. In: MUNSON RD (ed). Potassium in agriculture. Madison: American Society of Agronomy. p. 799-818.

SILVAFL; PINTO CABP; ALVES JD; BENITES FRG; ANDRADE CM; RODRIGUES GB; LEPRE AL; BHERING LP. 2009. Caracterização morfofisiológica de clones precoces e tardios de batata visando à adaptação a condições tropicais. Bragantia 68: 295-302.

SOUSA VF; COELHO EF. 2001. Manejo de fertirrigação em fruteiras. In: FOLEGATTI MV (ed). Fertirrigação: flores, frutas e hortaliças. Guaíba: Agropecuária. p. 289-317.

STALHAM MA; ALLEN EJ; ROSENFELD AB; HERRY FX. 2007. Effects of soil compaction in potato (Solanum tuberosum) crops. Journal of Agricultural Science 145: 295-312.

TEKALIGN T; HAMMES PS. 2005. Growth and productivity of potato as influenced by cultivar and reproductive growth. I. Stomatal conductance, rate of transpiration, net photosynthesis, and dry matter production and allocation. Scientia Horticulturae 105: 13-27.

WALLIN JR. 1962. Summary of recent progress in predicting late blight epidemics in United States and Canada. American Potato Journal 39: 306-312.

YORINORI GT. 2003. Curva de crescimento e acúmulo de nutrientes pela cultura da batata cv. 'Atlantic'. Piracicaba: USP-ESALQ. 66p (Dissertação mestrado). 